\title{
Analytical Investigation of the Applicability of Seismic Devices for Core Frames System in High-Rise Buildings
}

\author{
Dyah Kusumastuti ${ }^{1}$, Muslinang Moestopo ${ }^{1}$, Mega Suci Ramadhita ${ }^{1}$, Erwin Lim ${ }^{1}$, Randy Tanderan ${ }^{2}$, \\ Undagi Kausar Akbar ${ }^{1}$ \\ ${ }^{l}$ Department of Civil Engineering, Institut Teknologi Bandung \\ ${ }^{2}$ Department of Architecture and Building Engineering, Tokyo Institute of Technology
}

\begin{abstract}
The use of link element in high rise buildings has been applied widely and proven to be effective in the eccentric braced frame system. Latest research has also shown that the applicability of link element can be extended to other type of structural systems, such as: coupled wall system or structures with core wall. The research showed that the use of link element could lead to better deformation capacity of the system and the link elements could act as a "fuse" to limit the input of earthquake force. However, the improvement of the seismic behavior may not be effective for any type of structural system. This paper investigates analytically parameters affecting the effectiveness of the application of shear link elements within a structural system. Several parameters being studied are the relative stiffness between link element and structural stiffness, types of structural configuration, etc.
\end{abstract}

Keywords—deformation capacity, effective configuration, link beam, seismic behavior

\section{INTRODUCTION}

M any high rise building in Indonesia utilizes shear wall as lateral load-resisting system, which sometimes is combined with moment resisting frame system. Structures with shear wall are usually stiffer than frame system. Hence, the shear wall structures are less possible to have excessive deformation and damage. In many high rise building, openings in shear wall is necessary to accommodate windows, doors, or both. It is also a common to use shear walls as elevator shaft. If the openings are placed regularly, the structure can be highly efficient and possess ductile response with good energy dissipation characteristics. These walls are generally referred to coupled-shear walls.

In a coupled shear wall system, coupling beams are designed as deformation-controlled elements (DCEs) to dissipate energy, while all other elements are designed stronger than the coupling beams or as force-controlled elements (FCEs). Using this mechanism, the amount of energy dissipation depends on the yield moment capacity and plastic rotation capacity of the coupling beams. However, this system would cause damage to coupling beams and might be difficult to repair. Therefore, in some systems, a steel link beam is placed in the mid span of each coupling beam, so that damage would be concentrated on link beams and could be replaceable.

The link beams which connect coupling beams could act as mechanical dampers and should be designed as the only element to perform plastic deformation. This will certainly control the building damages due to severe earthquake to be located mostly at the link beams. The behavior of this steel core frame is similar to an eccentric braced frame (EBF) system. However, the use of link beam to dissipate energy might not be applicable to every structural system. In order to activate the link element as a fuse, a certain amount of lateral deformation is needed. It is argued that the stiffer the system, the less effective would the energy dissipated by the link be and vice versa. Therefore, three structural systems are evaluated in this study to investigate the important parameters affecting the effectiveness of links.

\section{MODELING AND DESIGN}

\subsection{Behavior of Links}

In general, link beams have two major forces; shear and flexural moment as shown in Fig. 1. Lateral forces on the structure will cause link beams to undergo a constant shear forces along it length. This shear forces create moment forces at both end in the same direction. By having both shear and flexural moment, link beams have two failure option; shear mechanism or flexural mechanism.

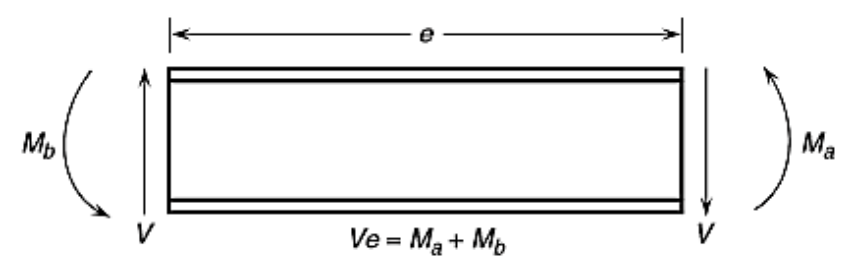

Figure 1. Free-body diagram of a link [1]

The relationship between moment (M) and shear (V) on link can be expressed in Figure $\mathbf{1}$ and shown in Eq. (1):

$$
V=\frac{M_{a}+M_{b}}{e}=\frac{2 M_{p}}{e}
$$

where $M_{a}$ and $M_{b}$ are Moment at right and left of beam, respectively, $e$ is the length of link, and $M_{p}$ is the plastic moment of link. By its failure mechanism, links can be classified into three types; a short or shear link (developing only shear yielding), a long or moment link (developing only flexural yielding), or an intermediate link (developing both shear and flexural yielding). The 
effect of link length on the failure mode and deformation capacity is illustrated in Figure 2.

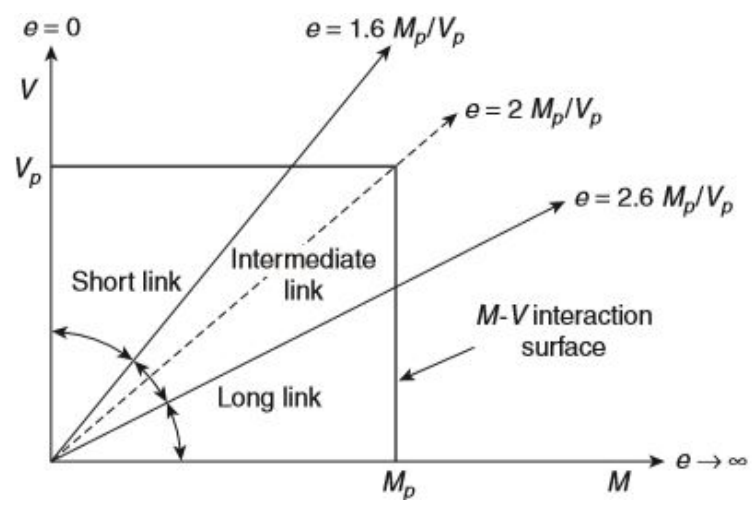

Figure 2. Classification of Links [1]

A short link $\left(\mathrm{e}<1.6 \mathrm{M}_{\mathrm{p}} / \mathrm{V}_{\mathrm{p}}\right)$ that has closely spaced stiffeners are proven to be effective in preventing shear buckling. Relatively uniform shear yielding in the web occurred along the entire link length, thus producing a large deformation capacity. On the other hand, flexural buckling occurred primarily in the form of flange local buckling on a long link $\left(\mathrm{e}>2.6 \mathrm{M}_{\mathrm{p}} / \mathrm{V}_{\mathrm{p}}\right)$. The deformation capacity is very limited as the link web did not yield along its length and contribute any plastic deformation. On an intermediate link $\left(1.6 \mathrm{M}_{\mathrm{p}} / \mathrm{V}_{\mathrm{p}}<\mathrm{e}<2.6 \mathrm{M}_{\mathrm{p}} / \mathrm{V}_{\mathrm{p}}\right)$ both shear and flexure are dominating in this case, where the plastic deformation was contributed by flexure buckling in the flanges and web shear buckling in the end panels.

As shown in Figure 3, applying simple plastic theory, the kinematics of the plastic mechanism requires that

$$
\gamma_{p}=\frac{L}{e} \theta_{p}
$$

where $\theta_{\mathrm{p}}$ is the plastic story drift angle (or plastic story drift ratio), $L$ is the span length, and $\gamma_{p}$ is the plastic deformation demand of the link. The expression shows that $\gamma_{p}$ increases rapidly as the link length is reduced. Because the elastic component of the total drift angle is generally small, the plastic story drift angle, $\theta_{\mathrm{p}}$, can be conservatively estimated as the total story drift divided by the story height, $\mathrm{h}$ :

$$
\theta_{p} \approx \frac{\Delta_{s}}{H}=\frac{C_{d} \Delta_{s}}{H}
$$

where $\Delta_{s}$ is the story drift produced by the prescribed design earthquake force, and $C_{d}$ is the deflection amplification factor.

The plastic link rotation angle is the inelastic angle between the link and the beam outside the link when the total story drift is equal to the design story drift, $\mathrm{C}_{\mathrm{d}} \Delta_{s}$. The plastic link rotation, $\gamma_{\mathrm{p}}$ should not exceed the inelastic deformation capacity of the link, i.e. :

- Link length of $e \leq 1.6 M_{p} / V_{p} \quad: 0.08 \mathrm{rad}$

- Link length of $e \geq 2.6 M_{p} / V_{p} \quad: 0.02 \mathrm{rad}$

Therefore, to develop the coupling beam with shear link as the seismic device, the shear link ( $e \leq$ $1.6 M_{p} / V_{p}$ ) should exhibit the plastic link rotation angle equal or more than 0.08 rad as shown in Figure 4.

\subsection{Numerical Modeling, Design, and Analysis}

This study investigates a 20-storey building with three different structural configurations. The typical building plan was indicated in Figure 5. In x-direction, concentrically braced frame system was adopted.

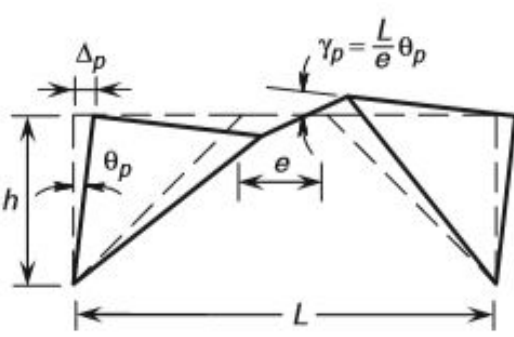

(a)

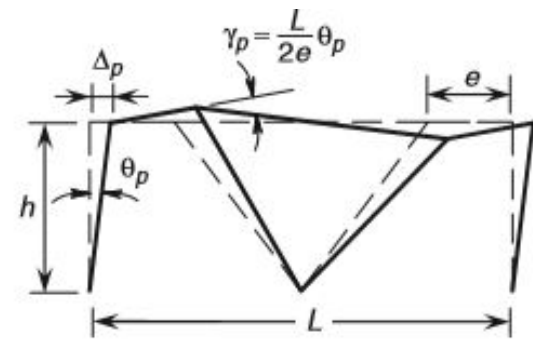

(b)

Figure 3. Link Rotation Demand [1]
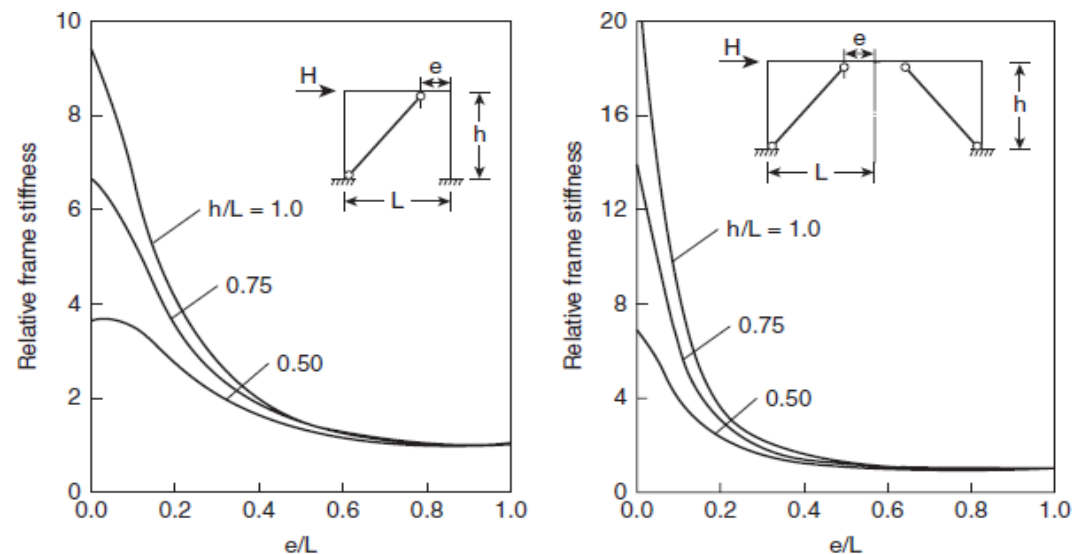

Figure 4. Link Rotation Demand [1] 


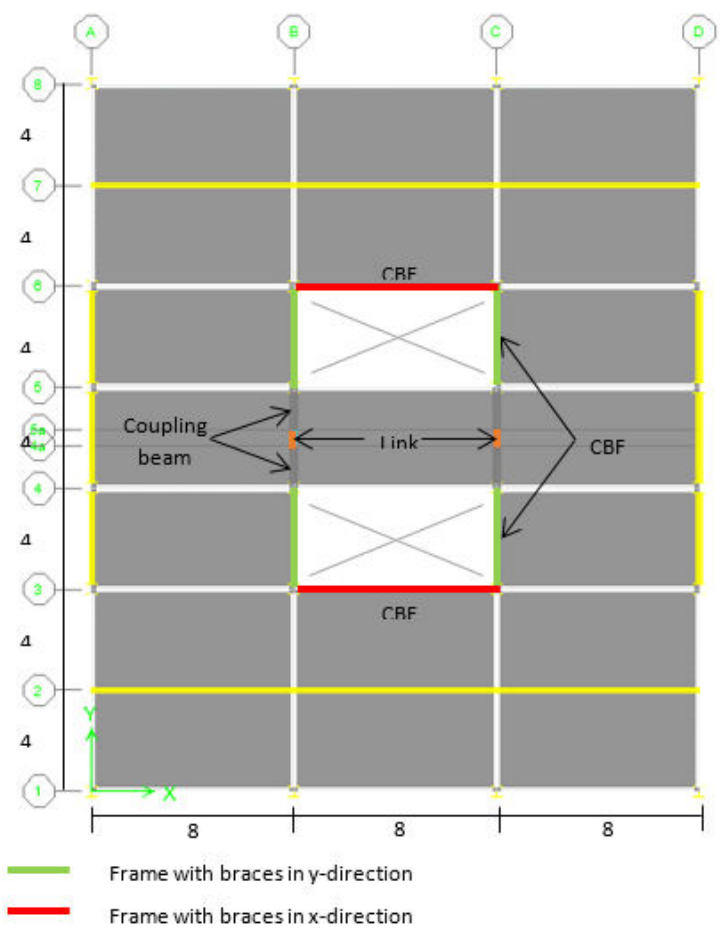

Figure 5. Building Plan

Meanwhile, in y-direction, core frame system with coupling beam and link beam was adopted. The gravity loads assigned to each floor were: dead load due to selfweight; super-imposed dead load of $50 \mathrm{~kg} / \mathrm{m}^{2}$ for roof story and $150 \mathrm{~kg} / \mathrm{m}^{2}$ for other stories; live load of 100 $\mathrm{kg} / \mathrm{m}^{2}$ for roof story and $250 \mathrm{~kg} / \mathrm{m}^{2}$ for other stories. Meanwhile, earthquake load was analyzed using response spectrum analysis. It was assumed that this building was located in Jakarta with soil type of SE. According to SNI 1726:2012 [2], the response spectrum is shown in Figure 6. In defining the Response Modification Factor (R), a value of 6 is used.

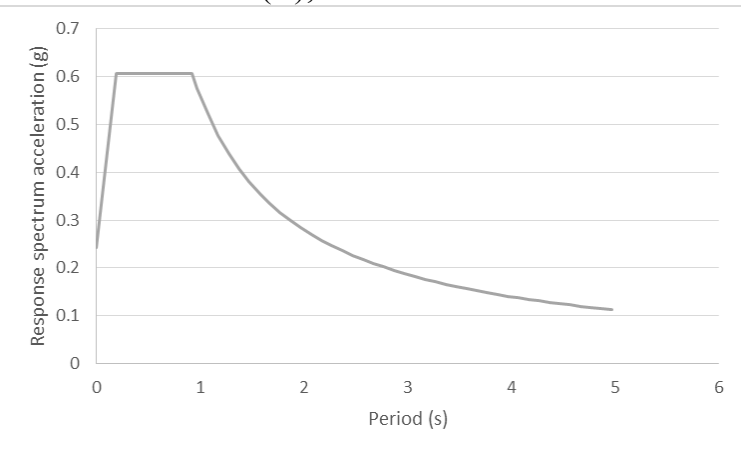

Figure 6. Design Response Spectrum [3]

The main parameters investigated in this study is the configuration of core frame, referred as Model 1, Model 2, and Model 3 and shown in Figure 7. The main difference among these three models is the presence of columns within the core frame from bottom to top. Model 1 which serves as a bench mark model, was modeled with complete columns within the core frame. In Model 2, the base columns in the core frame were eliminated. Meanwhile, in Model 3, all columns along the building height were eliminated. The elimination of core columns were expected to represent different stiffness of system. More link rotation to maximize the link yielding mechanism was expected as more core columns were eliminated from the benchmark model. However, in the later analysis, it was found out that performance point could not be located for Model 3 if $\mathrm{R}$ equals 6 was adopted. Therefore, additional analysis, refered as Model 4 was conducted. Model 4 and Model 3 share similar geometry. The only difference between Model 3 and Model 4 is the R factor. Model 4 adopted $\mathrm{R}$ value of 4 . The $\mathrm{R}$ factor for each model is presented in Table 1.

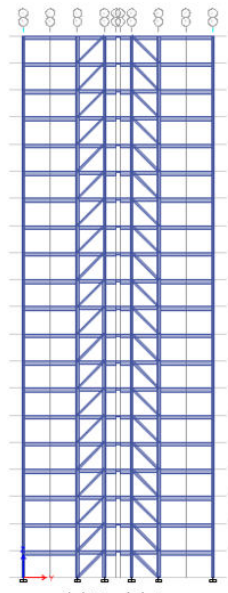

(a) Model 1

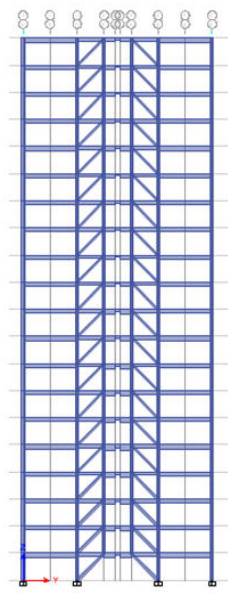

(b) Model 2

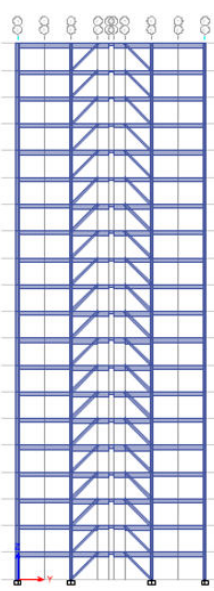

c) Model 3 and Model
4

Figure 7. Building Model (y-direction)

The analysis and design of these buildings were carried out using SAP 2000 [3] according to SNI 1726:2012 [2] and SNI 1729:2015 [4]. The design procedure is shown in Figure 8, where four major steps were involved: (1) determination of building geometry, initial element size, and load criteria, (2) design of link element as a deformation-controlled element, (3) design of other elements as force-controlled elements using capacity design concept, and (4) checking of failure mechanism through pushover analysis.

In the first step, the building was modeled using SAP 2000 with initial size of elements. Next, Using the loading criteria described in the previous paragraph and loading combination defined in the Code $[2,4]$, the SAP 2000 software was operated to design link elements $[1,4]$ as deformation-controlled elements. Later on, using the link capacity ratio $\left(\mathrm{V}_{\mathrm{p}} / \mathrm{V}_{\mathrm{n}}\right)$, a scale factor is determined to amplify the earthquake force. The amplified earthquake force is then used to design all other force-controlled elements (coupling beam, beam, bracing, inner and outer columns). This step is also known as the capacity design approach. Finally, pushover analysis was carried out. There were at least two purposes of the pushover analysis, i.e.: (1) to ensure no yielding occurred outside link elements and (2) to obtain structural capacity. Using the aforementioned procedure, the final member size for all elements are tabulated in Tables 2 to 5 for Models 1 to 4 , respectively. 


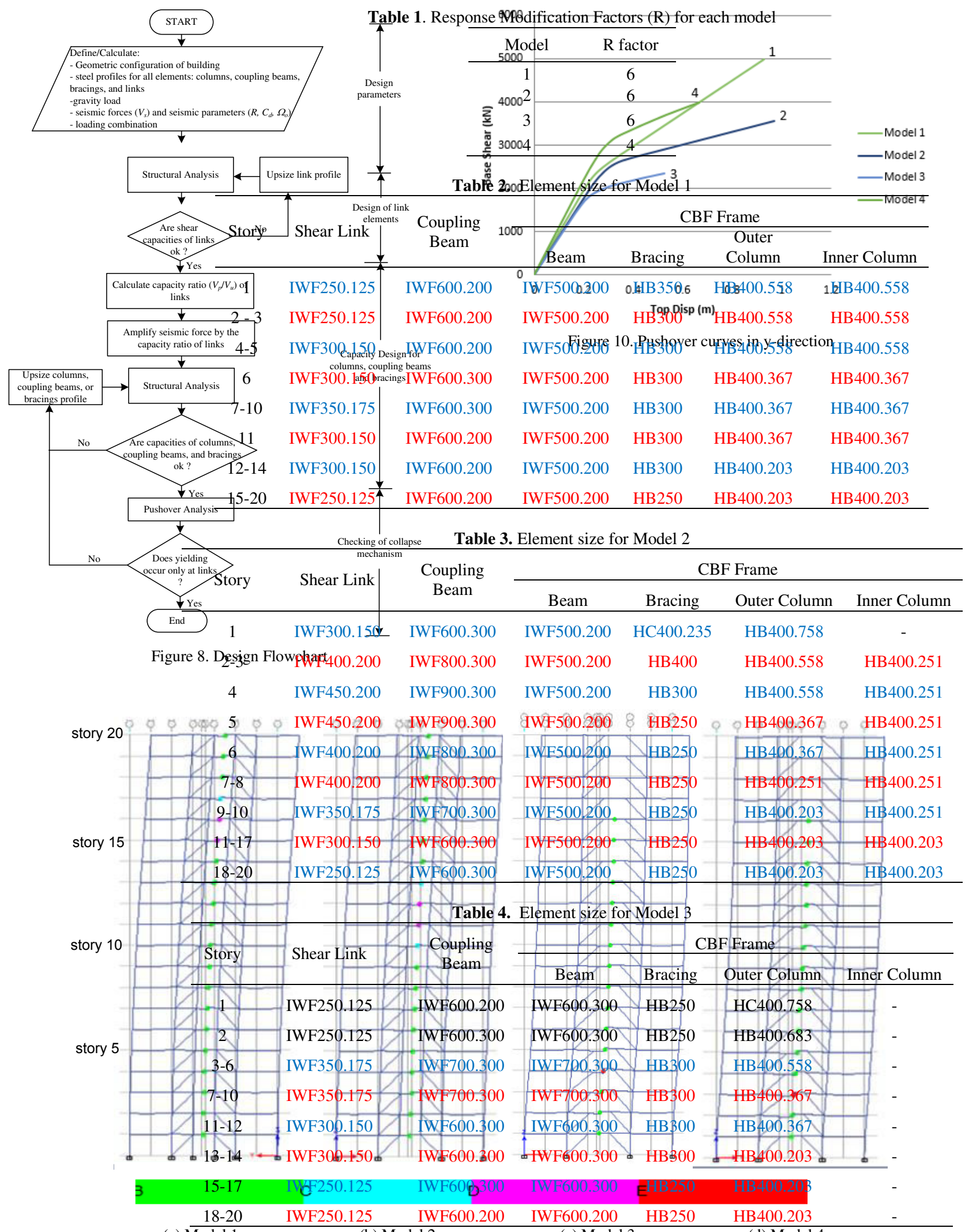

$\begin{array}{rrr}\text { (a) Model } 1 & \text { (b) Model } 2 & \text { (c) Model } 3 \\ \text { Figure 9. Formation of Hinges (y-direction) }\end{array}$

\section{RESULTS AND DISCUSSION}

For each model, pushover analysis was carried out and performance point was obtained using capacity spectrum method. Results and findings of each model are presented and discussed in the followings.
Before conducting push-over analysis, a non-linear hinge conforming to FEMA 356 [5] was assigned to each link. The formation of plastic hinges in each model are presented in Figure 9.

Formation of plastic hinges in Model 1 shows that all plastic hinges in links were formed and those located at story 15 and beyond experienced the largest rotation 
demand (Figure 9a). Similar observation was made for Model 2, but locations of links where rotation demand is the largest shifted to story 11 to 13 (Figure 9b). In Figure 9c and 9d, it could be seen that links located at stories 16 and beyond did not yield for Model 3 and
Performance points for each model was determined using capacity spectrum method recommended in ATC 40 [6]. Results of this analysis are presented in Figure 11 and Table 6. From the performance point, the lateral deformation capacity of Model 2 is better compared than

Table 5. Element size for Model 4

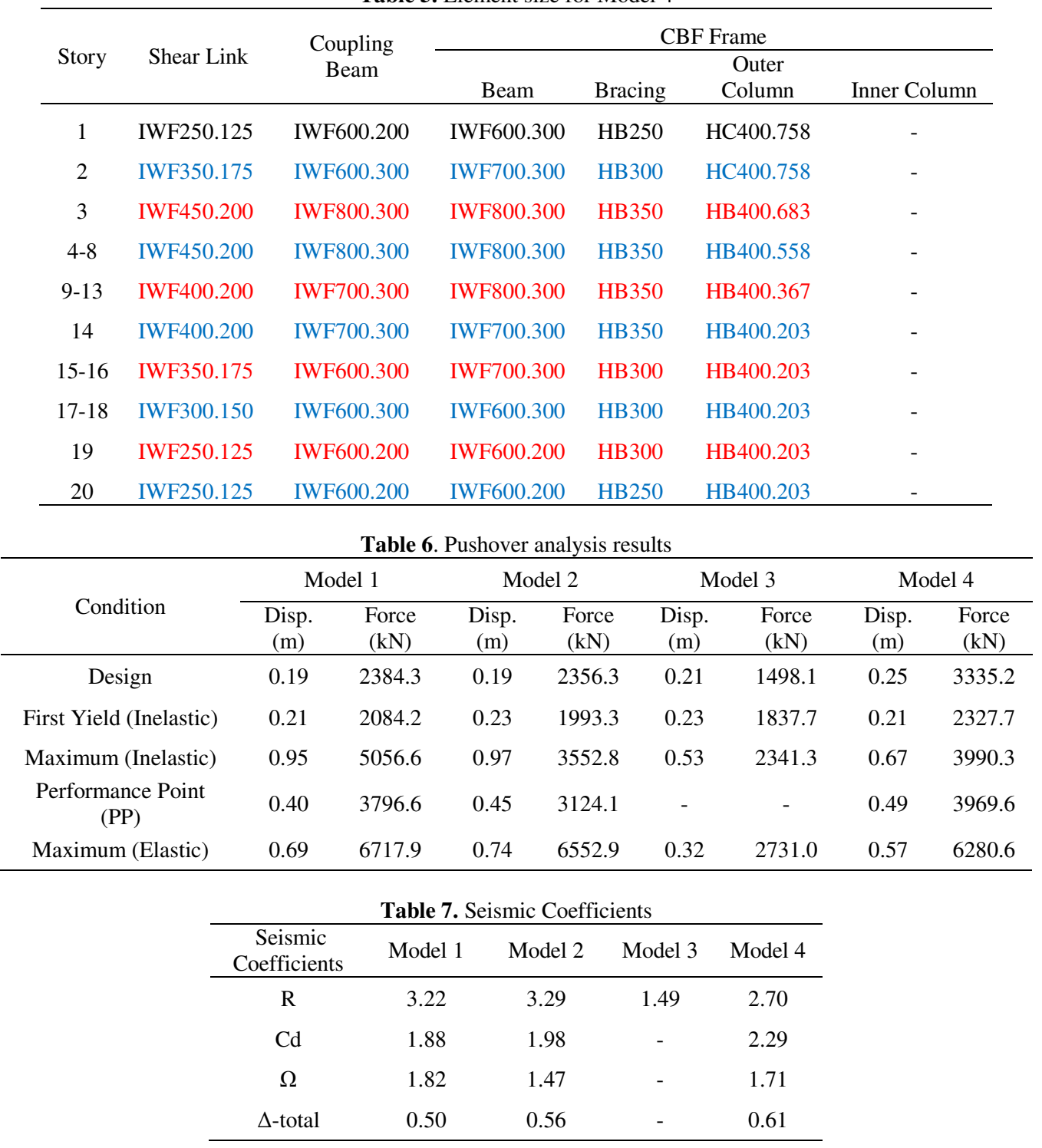

Model 4, respectively.

Pushover analysis shows that the first yield of each model occurred earlier than the design value as indicated in Table 6. Using $\mathrm{R}$ value equals 6 , the first yield of Model 1 occurred at $2084.2 \mathrm{kN}$ while the design base shear was $2384.3 \mathrm{kN}$. Similarly, first yield and design base shear for Model 2 were $1993.3 \mathrm{kN}$ and $2356.3 \mathrm{kN}$, respectively; and first yield and design base shear for Model 3 were $1837.7 \mathrm{kN}$ and $1498.1 \mathrm{kN}$, respectively. However, if $\mathrm{R}$ equals 4 is used for Model 4 , the first yield occured at $2327.7 \mathrm{kN}$, while the design base shear was $3335.2 \mathrm{kN}$. Comparison of the pushover curves of each model is presented in Figure 10. It can be observed that Model 4, followed by Model 1 are stiffer than the other two models. It implies that yielding of structures in Model 4 and Model 1 would begin at a later stage and at a larger force than the other two models. that of Model 1 ( $0.45 \mathrm{~m}$ compared to $0.40 \mathrm{~m}$ for Model 1 and Model 2, respectively). However, using $\mathrm{R}$ equals 6 , no performance point could be obtained for Model 3. If $\mathrm{R}$ equals 4 is used as in Model 4, it would result in lateral deformation capacity and maximum lateral strength as large as $0.49 \mathrm{~m}$ and $3969.6 \mathrm{kN}$, respectively.

Related to the seismic coefficients presented in Table 7, the $\mathrm{R}$ value was defined as the force at performance point divided by the force at first yield. Meanwhile, the $C_{d}$ value is defined as the displacement at performance point divided by the displacement at first yield. Table 5 shows that the Response Modification Factor (R) for Model 1 and Model 2 were quite similar, which are 3.22 and 3.29, respectively. Meanwhile, the displacement amplification factor $\left(C_{d}\right)$ value of Model 2 is slightly better than that of Model 1 . 


\section{CONCLUSIONS}

Several models with different geometry configurations and different relative stiffness between link elements and structural system has been analyzed. Some conclusions which can be drawn as as follows:

a. Link elements could work well in all models to dissipate energy, indicated by yielding of link elements while remaining structural elements are still in elastic range.

b. Model 1 which represents a relatively stiff structural system has a slightly lower lateral deformation capacity compared to Model 2 and Model 3.

c. Model 2 could be considered as the most efficient system (among three investigated configurations) as all links at different building heights yielded and possessed better deformation capacity (compared to Model 1, which was designed using similar $\mathrm{R}$ value).

d. When $\mathrm{R}$ value is reduced from 6 to 4 , structures with configuration as in Model 4 could achieve high deformation capacity.

\section{ACKNOWLEDGEMENT}

The authors would like to thank AUN/SEED-Net Project No. ITB CRI 1501 and 1601 for the funding and
Program Penelitian, Pengabdian kepada Masyarakat dan Inovasi (P3MI) ITB for the continuous support of this research. The authors also extend their gratitude to Prof. Kazuhiko Kasai and Prof. Satoshi Yamada for their advice and discussion as well as to Nippon Steel and Sumitomo Metal Corporation for counterpart-fund and kind support.

\section{REFERENCES}

[1] Bruneu, M., Uang, C. M., and Sabelli, R. Ductile Design of Steel Structures $2^{\text {nd }}$. McGraw-Hill Companies, Inc., 2011, 924 pp.

[2] SNI 1726:2012. Tata Cara Perencanaan Ketahanan Gempa untuk Struktur Bangunan Gedung dan Non-gedung. Badan Standardisasi Nasional, Jakarta, 2012, 138 pp.

[3] SAP 2000, Structural Analysis Program 2000. CSI, Berkeley, CA.

[4] SNI 1729:2015. Spesifikasi untuk Bangunan Gedung Baja Struktural. Badan Standardiasi Nasional, Jakarta, 2015, 242 pp.

[5] FEMA 356. Prestandard and Commentary for the Seismic Rehabilitation of Buildings. Federal Emergency Management Agency, Washington, D. C., 2000,

[6] ATC 40. Seismic Evaluation and Retrofit of Concrete Buildings. Applied Technology Council, Redwood City, CA, 1996, 345 pp. 